\title{
Dynamic Optimization Research on the Section Morphology of Large-span Tunnels in Shallow Rock Mass
}

\author{
Wang Hui ${ }^{1,2}$ and Wang Qing-biao ${ }^{1, *}$
}

\begin{abstract}
${ }^{I}$ Department of Resources and Civil Engineering, Shandong University of Science and Technology, Tai'an, Shandong, 271019, P.R. China; ${ }^{2}$ Geotechnical \& Structural Engineering Research Center of Shandong University, Jinan, Shandong, 250061, P.R. China
\end{abstract}

\begin{abstract}
The optimization design of the section morphology of large-span tunnels plays an important role for saving cost and improving the engineering stability. The flat ratio of tunnel which is as an important control index, its rationality is the key problem in the design of tunnels. Program with Python to set up the dynamic calculation model of a large-span tunnel planned to be constructed which can be run and analyzed in ABAQUS. The MATLAB language is used to compile the optimization analysis program based on genetic algorithm, and then the dynamic calculation model is embedded into it. Using excavation area, plastic zone, ground surface settlement, vault subsidence, etc. as optimal objective to make dynamic analysis for the model and put forward the reasonable flat ratio of the supported project. The result of this paper provides reference for the section optimization design of similar tunnel engineering.
\end{abstract}

Keywords: Dynamic optimization, large-span tunnels, section morphology.

\section{INTRODUCTION}

With the rapid development of China, three-lane and four-lane highway tunnel engineering in single hole is increasing. But from the current situation, due to many complex factors which affect the stability of the surrounding rock of shallow buried tunnels, coupled with the large span and decreasing of rise-span ratio, the structure stress is more complicated. Problems exist in the structure design, construction and other aspects of super-large section tunnel. So as an important control index, determination of the flat ratio is the key problem in tunnel design.

Gong Jianwu established finite element models of tunnels with different span to analyze the mechanics characteristic and the stability of surrounding rock in the tunnel construction process [1]. Yang Wanbin took the total damage area of surrounding rock as the objective function to optimize the section form of underground caverns [2]. G. Ren used the condition of distribution after tunnel excavation to study the optimal design of the section form [3]. Using the tunnel structure minimum cost as objective function, Cai Xin established different calculation models to seek for the optimal design scheme of the tunnel structure section size [4]. LV Aizhong proposed the maximum tangential stress of cavern surrounding rock to be minimum as the optimal criterion and put forward the method to determine the optimal cavern shape by using complex optimization technique [5]. The above research shows that, the design of the section morphology has been staying in experience analogy or comparison of several different schemes $[6,7]$.

*Address correspondence to this author at the Department of Resources and Civil Engineering, Shandong University of Science and Technology, Tai'an, Shandong, 271019, P.R. China; Tel: 18805381111;

E-mail: 1349725165@qq.com
The choice of tunnel cross section is a comprehensive process which should be considered the economy, safety, technology and other factors. Based on this idea, Program with Python to set up the dynamic calculation mode of a large-span tunnel planned to be constructed which can be run and analyzed in ABAQUS. The MATLAB language is used to compile the optimization analysis program based on genetic algorithm. Using excavation area, plastic zone, ground surface settlement, vault subsidence, etc. as optimal objective to make dynamic analysis for the model and put forward the reasonable flat ratio of the supported project.

\section{THE DYNAMIC TUNNEL MODEL OF DIFFERENT SECTION MORPHOLOGY}

\subsection{Dynamic Tunnel Model}

The reasonable flat ratio is helpful to improve the space utilization of the tunnel, enhance the stability of the surrounding rock, and ensure the safety of the tunnel construction and the economic rationality during operation. How to determine the reasonable flat ratio becomes the key problem in the design of large span tunnel. A tunnel proposed to be constructed is composed of eight lanes and the maximum buried depth is $58 \mathrm{~m}$. The design excavation width is 18.65 $\mathrm{m}$. Due to the engineering geological conditions, linear programming and other factors, it has the characteristics of large span, buried depth and poor stability of surrounding rock.

Based on the idea of parametric modeling and calculation of Python language to realize the automatic cycle modeling, meshing, adjusting the flat ratio of tunnel, automatic calculation and form the corresponding calculation results of different scheme files finally. According to the engineering geological conditions, programming and tunnel section excavation characteristics of the supported project, the scope of the 
tunnel flat ratio $(\mathrm{R}=\mathrm{T} / \mathrm{L})$ is determined from 0.53 to 0.61 . The scheme of dynamic model of the large-span tunnel is shown in Fig. (1). The scheme of the large-span tunnel for section morphology optimization is shown in Fig. (2).

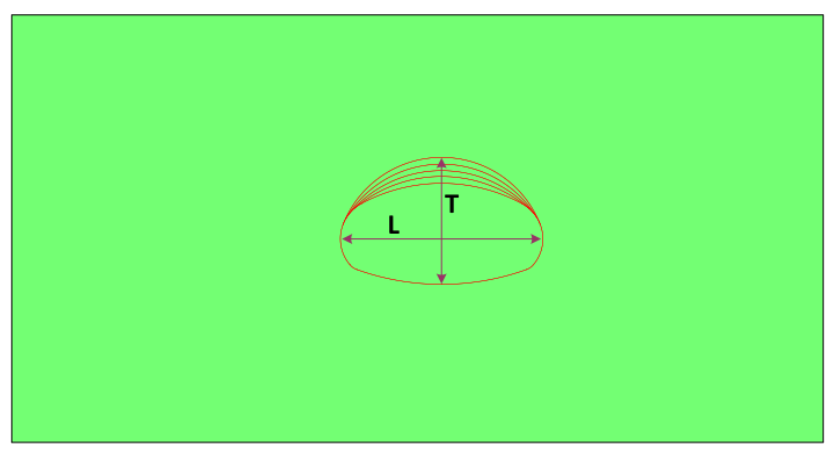

Fig. (1) Dynamic model of the large-span tunnel.

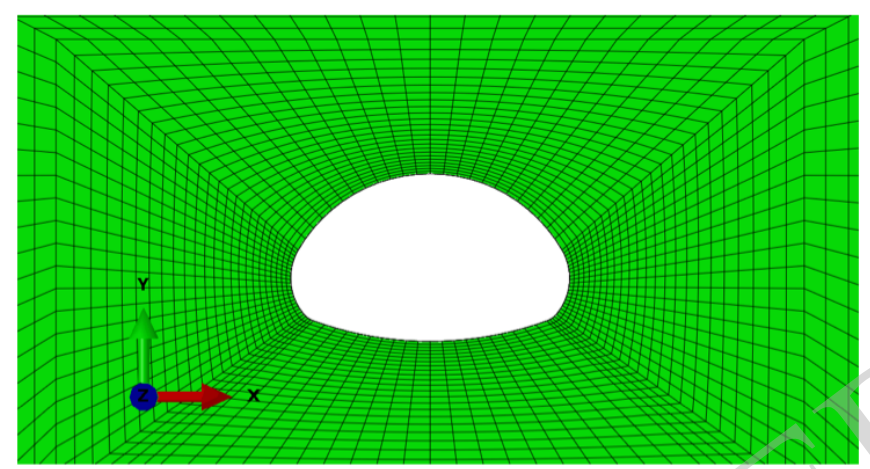

Fig. (2) Finite element model of the large-span tunnel for section morphology optimization.

\subsection{Mechanics Parameters and Constitutive Model of Surrounding Rock}

In numerical simulation process, plane strain element and beam element are used to analyze the characters of surrounding rock and lining respectively. Due to the shallow buried depth and development of rock joints and fissures, Jointed material model of ABAQUS [8-9] is used to simulate the engineering properties of the jointed rock mass of the supported project. The sliding rule of the failure plane of this model can be expressed as :

$f_{\mathrm{a}}=\tau_{\mathrm{a}}-p_{\mathrm{a}} \tan \beta_{\mathrm{a}}-d_{\mathrm{a}}=0$

Where, $f_{\mathrm{a}}$ is the sliding failure surface of the jointed system a, $\tau_{\mathrm{a}}$ is the component of the shear stress on the joint surface, $p_{\mathrm{a}}$ is the vertical pressure which impacts on the joint surface, $\beta_{\mathrm{a}}$ is the friction angle for system a, $d_{\mathrm{a}}$ is the cohesion for system a. From equation (1), As long as $f_{\mathrm{a}}<0$, joint system a does not slip. When, $f_{\mathrm{a}} \geqslant 0$ joint system a slips.

In addition, from the aspects of material failure, the failure mechanism of Jointed material model is based on the Drucker-Prager failure criterion. Its expression can be shown as:

$q-p \tan \beta-d=0$
Where, $q$ is Mises equivalent stress. $p$ is hydrostatic pressure. $\beta$ and $d$ are the internal friction angle and cohesion of Drucker-Prager model.

Properties of surrounding rock and lining materials is shown in Table 1. In order to reduce the boundary effect, the upper boundary is to ground. The lower boundary is $100 \mathrm{~m}$ below the bottom of tunnel. The distance between the left and right boundary is $360 \mathrm{~m}$. The tunnel is located in the middle position of the model. Horizontal restraint is imposed on the left and right boundary. Vertical restraint is imposed on the top and bottom boundary. During numerical simulation of the construction process, the lining supports are applied directly after tunnel excavation.

\section{DYNAMIC OPTIMIZATION OF THE TUNNEL SECTION MORPHOLOGY}

\subsection{Parameter Optimization Model}

In this paper, the optimization parameter is the tunnel flat ratio $(R)$. The basic idea of the optimization is considering the factors including excavation area, deformation of tunnel surrounding rock after excavation, the impact on the lining, etc. Calculate the optimization parameters within its scope, analyze the calculation results automatically and calculate the objective function value. When the optimal objective function value is up to minimum, the optimization parameter is optimal.

Through the above analysis, tunnel excavation area $\left(F_{1}\right)$, horizontal convergence $\left(F_{2}\right)$, surface settlement $\left(F_{3}\right)$, vault subsidence $\left(F_{4}\right)$, maximum bending moment $\left(F_{5}\right)$ and axial force $\left(F_{6}\right)$, the plastic zone of vault area $\left(F_{7}\right)$ can be calculated by finite element parametric model. It can be expressed as follows:

$F_{n}=f(R), n=1,2, \ldots, 7$

From equation (3), $F_{n}$ is a function of the tunnel flat ratio $(R)$. When the flat ratio $(\mathrm{R})$ changes, the calculation parameters of $F_{1}, F_{2}, F_{3}, F_{4}, F_{5}, F_{6}$ and $F_{7}$ will change too.

In the optimization problem of the tunnel flat ratio, the total objective function expression can be shown as:

$G=\sum_{1}^{n} \frac{F_{n}}{F_{n \max }},(n=7)$

Where, $G$ is the total objective function. $F_{n}$ is the corresponding individual objective function(tunnel excavation area $\left(F_{1}\right)$, horizontal convergence $\left(F_{2}\right)$, surface settlement $\left(F_{3}\right)$, vault subsidence $\left(F_{4}\right)$, maximum bending moment $\left(F_{5}\right)$ and axial force $\left(F_{6}\right)$, the plastic zone of vault area $\left.\left(F_{7}\right)\right) . n$ is the number of the single objective function. $F_{n \max }$ is the maximum value which is got by the calculation of the single target function within its value range.

The parameter of the flat ratio is set within a certain range and its constraint condition is as follows:

$R_{\min } \leq R \leq R_{\max }$

Where, $R_{\min }$ and $R_{\max }$ are the allowable range of the optimization parameter. According to the engineering geological conditions, linear programming and the characteristics of 
Table 1. Properties of surrounding rock and lining materials.

\begin{tabular}{|c|c|c|c|c|c|}
\hline Classification & $\begin{array}{c}\text { Elastic Modulus } \\
\boldsymbol{E} / \mathbf{M P a}\end{array}$ & $\begin{array}{c}\text { Poisson ratio } \\
\boldsymbol{v}\end{array}$ & $\begin{array}{c}\text { Cohesion } \\
\boldsymbol{c} / \mathbf{M P a}\end{array}$ & $\begin{array}{c}\text { Internal Friction } \\
\text { Angle } \varphi /\left(\mathbf{(}^{\circ}\right.\end{array}$ & $\begin{array}{c}\text { Density } \\
/\left(\mathrm{g} / \mathbf{c} \cdot \mathbf{m}^{\mathbf{3}}\right)\end{array}$ \\
\hline \hline Jointed Rock Mass & 2000 & 0.35 & 0.55 & 30 & 2.0 \\
\hline Lining & 30000 & 0.15 & - & - & 2.5 \\
\hline
\end{tabular}

Table 2. Parameter settings to be optimized and optimal result.

\begin{tabular}{|c|c|}
\hline Parameter & Flat ratio $(\boldsymbol{R})$ \\
\hline \hline Value range & $0.51 \sim 0.63$ \\
\hline Design value & 0.55 \\
\hline Optimal result & 0.5958 \\
\hline
\end{tabular}

Table 3. Comparison of optimal objective between initial value and optimal value.

\begin{tabular}{|c|c|c|c|c|c|c|c|}
\hline Parameter & $\begin{array}{c}\boldsymbol{F}_{\mathbf{1}} \\
/ \mathbf{m}^{2}\end{array}$ & $\begin{array}{c}\boldsymbol{F}_{\mathbf{2}} \\
/ \mathbf{m m}\end{array}$ & $\begin{array}{c}\boldsymbol{F}_{\mathbf{3}} \\
/ \mathbf{m m}\end{array}$ & $\begin{array}{c}\boldsymbol{F}_{\mathbf{4}} \\
/ \mathbf{m m}\end{array}$ & $\begin{array}{c}\boldsymbol{F}_{\mathbf{5}} \\
/ \mathbf{K N} . \mathbf{m}\end{array}$ & $\begin{array}{c}\boldsymbol{F}_{\mathbf{6}} \\
/ \mathbf{K N}\end{array}$ & $\begin{array}{c}\boldsymbol{F}_{\mathbf{7}} \\
/ \mathbf{m}^{2}\end{array}$ \\
\hline \hline design value & 150.77 & 3.73 & 1.35 & 4.76 & 125.0 & 4221.5 & 20.69 \\
\hline optimal value & 160.86 & 4.20 & 1.21 & 4.20 & 128.7 & 4239.9 & 11.01 \\
\hline
\end{tabular}

tunnel section excavation, $R_{\min }=0.53$ and $R_{\max }=0.61$ are determine.

The process of parameter optimization is to find the optimal flat ratio within its allowable range, which can make the value of the total objective function $(G)$ to minimum.

\subsection{Program Development}

Based on the theory and method proposed in this paper, use the general-purpose finite element software ABAQUS and its standard design language Python to write programs which can read tunnel excavation area $\left(F_{1}\right)$, horizontal convergence $\left(F_{2}\right)$, surface settlement $\left(F_{3}\right)$, vault subsidence $\left(F_{4}\right)$, maximum bending moment $\left(F_{5}\right)$ and axial force $\left(F_{6}\right)$, the plastic zone of vault area $\left(F_{7}\right)$. Write the optimization analysis program based on genetic algorithm with MATLAB language and combined with the finite element algorithm of ABAQUS to optimize the flat ratio of the tunnel.

\subsection{The Optimization Results Analysis}

According to the proposed optimization method and idea, the tunnel flat ratio is optimized. Before the end of the optimization calculation, the finite element program of ABAQUS is called to calculate for 156 times. Parameter settings to be optimized and optimal result are shown in Table 2 .

Table 3 is the comparison of optimal objective between initial value and optimal value of flat ratio. Through the optimization of flat ratio within its allowable range, get its optimal value for the supported project which is 0.5958 . Compared with the calculation results of design value, it can be found that the optimal value has a good effect for maintaining the stability of tunnel surrounding rock.
In this paper, with reference to the literature [10] of calculation model and mechanical parameters of surrounding rock, use the proposed calculation method to make the optimization research on tunnel flat ratio. The calculation result of this paper has a good consistency to the optimal flat ratio which is equal to 0.59 in literature [10]. This also shows the correctness of this paper's conclusion.

\section{CONCLUSION}

(1) Program with Python to set up the dynamic calculation model of a large-span tunnel planned to be constructed which can be run and analyzed in ABAQUS.

(2) Write the optimization analysis program based on genetic algorithm with MATLAB language and the dynamic calculation model is embedded into it. Using excavation area, plastic zone, ground surface settlement, vault subsidence, etc. as optimal objective to make dynamic analysis for the model and put forward the reasonable flat ratio of the supported project. The results show that when the flat ratio is equal to 0.5958 , cross section shape achieves the best. Using the optimized scheme can improve the stability of surrounding rock well.

\section{CONFLICT OF INTEREST}

The authors confirm that this article content has no conflict of interest.

\section{ACKNOWLEDGEMENTS}

This work was financially supported by: 
(1) National Natural Science Foundation of China (NSFC) (51409154, 41372289);

(2) SDUST Research Fund(2014TDJH103);

(3) Scientific research foundation of Shandong University of Science and Technology for recruited talents(2013RCJJ029).

\section{REFERENCES}

[1] GONG Jian-wu, LEI Xue-wen. Numerical analysis of stability of surrounding rock for large-section tunnels with small spacing[J]. Rock and Soil Mechanics, 2010, 31(Supp.2): 412-417.

[2] YANG Wan-bin,XUE Xi-cheng. The optimized calculation method for spacing and cross section of underground tunnels $[\mathrm{J}]$. Chinese Journal of Geotechnical Engineering,2001,23(1) : 61-63.

[3] G. Ren,J.V. Smith,J.W. Tang,Y.M. Xie. Underground excavation shape optimization using an evolutionary procedure[J]. Computers and Geotechnics,2005,(32) : 122-132.

[4] CAI Xin,LI Hong-xuan,WU Ying-li,YI Jian-gang. Optimal design of structure of underwater tunnels[J]. Journal of Hohai University(Natural Sciences),2009,37 (6) : 665-668.
[5] Lv Ai-zhong. The Method for Optimum Shapes of Tunnels And Cavities[J]. Chinese Journal of Rock Mechanics and Engineering,1996,15(3) : 275-281.

[6] QU Hai-feng. An Overview on Construction and Research of Super-large Cross-section Tunnels with Low Height-span Ratios[J]. Tunnel Construction,2009, 29(2):166-171.

[7] ZHOU Ding-heng,CAO Li-qiao,MA Yong-feng, et al. Research on Construction Behaviors of Support System in Four-Lane Ultra Large-Span Tunnel with Super-Large Cross-Section[J]. Chinese Journal of Rock Mechanics and Engineering,2010,29(1) : 140-148.

[8] Hibbitt,Karlsson and Sorensen,Inc. ABAQUS theory manual and analysis user's manual[R]. Pawtucket,USA : Hibbitt,Karlsson and Sorensen,Inc.,2002.

[9] Zienkiewicz O C, Pande G N. Time dependent multilaminate model of rocks - a numerical study of deformation and failure of rock masses[J]. International Journal for Numerical and Analytical Methods in Geomechanics, 1977, 1: 219-247.

[10] CHEN Weiz-hong, WANG Hui, TIAN Hong-ming. Study of flat ratio optimization of large-span tunnel section in shallow broken rock mass $[\mathrm{J}]$. Chinese Journal of Rock Mechanics and Engineering,2011,30(7) : 1389-1395.

Received: May 26, 2015

Revised: July 14, 2015

Accepted: August 10, 2015

(c) Hui and Qing-biao; Licensee Bentham Open.

This is an open access article licensed under the terms of the (https://creativecommons.org/licenses/by/4.0/legalcode), which permits unrestricted, noncommercial use, distribution and reproduction in any medium, provided the work is properly cited. 